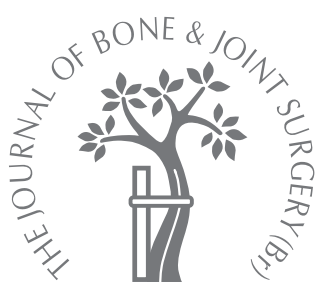

M. R. Utting ${ }^{\dagger}$, M. Raghuvanshi, R. Amirfeyz, A. W. Blom, I. D. Learmonth, G. C. Bannister

From Southmead Hospital, Bristol, England

\title{
The Harris-Galante porous-coated, hemispherical, polyethylene-lined acetabular component in patients under 50 years of age
}

\author{
A 12- TO 16-YEAR REVIEW
}

We have reviewed 70 Harris-Galante uncemented acetabular components implanted as hybrid hip replacements with cemented stems between 1991 and 1995 in 53 patients whose mean age was 40 years (19 to 49 ). The mean follow-up was for 13.6 years (12 to 16 ) with no loss to follow-up. We assessed the patients both clinically and radiologically.

The mean Oxford hip score was 20 (12 to 46) and the mean Harris hip score 81 (37 to 100) at the final review. Radiologically, 27 hips (39\%) had femoral osteolysis, 13 (19\%) acetabular osteolysis, and 31 (44\%) radiolucent lines around the acetabular component. Kaplan-Meier survival curves were constructed for the outcomes of revision of the acetabular component, revision of the component and polyethylene liner, and impending revision for progressive osteolysis.

The cumulative survival for revision of the acetabular component was $\mathbf{9 4 \%}(\mathbf{9 5 \%}$ confidence interval 88.4 to 99.7$)$, for the component and liner $84 \%$ (95\% confidence interval 74.5 to 93.5) and for impending revision $55.3 \%$ (95\% confidence interval 40.6 to 70 ) at 16 years.

Uncemented acetabular components with polyethylene liners undergo silent lysis and merit regular long-term radiological review.

One of the most difficult problems in total hip replacement (THR) is the management of the young patient. Failure of the acetabular component is the principal cause of revision in THR. ${ }^{1}$ Whereas newer generations of cementing techniques and improved design have increased the survival of cemented femoral components, ${ }^{2}$ they have not increased the longevity of cemented acetabular components in younger patients. ${ }^{1}$ Ballard et $\mathrm{al}^{3}$ found $36 \%$ of combined revision and radiological loosening of cemented acetabular components at a mean follow-up of 11 years, and Barrack, Mulroy and Harris, ${ }^{4}$ a $44 \%$ combined revision and radiological loosening rate at a mean followup of 12 years in patients under the age of 50 years. Boeree and Bannister ${ }^{5}$ noted a revision rate of $12.7 \%$ at 12 years for cemented acetabular components, with $27 \%$ of cases showing radiological evidence of failure in patients under the age of 50 .

Based on laboratory evidence of bone ingrowth into a porous surface ${ }^{6}$ and good intermediate-term results of uncemented metalbacked polyethylene-lined acetabular components, hybrid THR with cemented femoral and uncemented acetabular components has been used increasingly. ${ }^{7-14}$ Despite early encouraging results, the long-term durability of uncemented acetabular components in the young and active patient is yet to be proved. The aim of this study was to establish whether hybrid THR with the Harris-Galante I (Zimmer, Warsaw, Indiana) acetabular component gave improved results in the young, active population under 50 years of age.

\section{Patients and Methods}

Between February 1991 and August 1995, 70 Harris-Galante porous Type I acetabular components were implanted in 53 patients in a regional orthopaedic centre under the direct supervision of five consultants. There were 29 women and 24 men. All were under 50 years of age at the time of operation. The mean age was 40 years (19 to 49 ). The diagnoses before the THR are recorded in Table I. In 36 patients unilateral THR was undertaken and in 17 staged bilateral procedures were performed. In total, 56 acetabular components were implanted by consultants and 14 by senior trainees. A total of four different types of femoral component were used in conjunction with these implants (Table II).

In nine hips (six patients) prior surgery had been conducted, including three internal fixations of acetabular fractures, three containment osteotomies, one core decompression 
Table I. Pre-operative diagnoses

\begin{tabular}{ll}
\hline Diagnosis & $\begin{array}{l}\text { Number of } \\
\text { hips }\end{array}$ \\
\hline Idiopathic osteoarthritis & 29 \\
Developmental dysplasia of the hip & 18 \\
Avascular necrosis & 8 \\
Post-traumatic arthritis & 5 \\
Ankylosing spondylitis & 3 \\
Psoriatic arthropathy & 2 \\
Rheumatoid arthritis & 1 \\
Post-septic arthritis & 1 \\
Slipped capital femoral epiphysis & 1 \\
Spondyloepiphyseal dysplasia & 1 \\
Renal osteodystrophy & 1 \\
\hline
\end{tabular}

Table II. Cemented femoral components used

\begin{tabular}{ll}
\hline Femoral component type & $\begin{array}{l}\text { Number of } \\
\text { hips }\end{array}$ \\
\hline Collarless polished tapered (Zimmer, Warsaw, Indiana) & 31 \\
Exeter (Howmedica International, London, UK) & 29 \\
Sheehan (Zimmer) & 8 \\
Charnley (DePuy International, Leeds, UK) & 2 \\
\hline
\end{tabular}

for avascular necrosis, and two cannulated screw fixations for intracapsular fracture.

The Harris-Galante hemispherical component has a commercially-pure titanium shell covered externally with a mesh of titanium fibre and has multiple holes for supplementary screw fixation. In 68 hips (51 patients) the component was inserted with under-reaming of $2 \mathrm{~mm}$, and in two hips (two patients) in a line-to-line fashion. In 54 hips (40 patients) the acetabular components were secured with between two and five $4.5 \mathrm{~mm}$ diameter titanium screws. In 16 hips (13 patients) no screws were required. The surgical approach used was posterior in 52 hips (37 patients), transgluteal in 17 (15 patients), and transtrochanteric in one. In 43 hips (31 patients) a $28 \mathrm{~mm}$ femoral head was implanted, in 20 hips (15 patients) a $22 \mathrm{~mm}$ head, and in seven hips (seven patients) a $32 \mathrm{~mm}$ femoral head, in each case matched to the appropriate size of the polyethylene liner, which is held in place by a tine mechanism.

Second-generation cementing techniques were used, ${ }^{15}$ and a cemented femoral component was employed in all cases. All patients were allowed to bear full weight as tolerated immediately after their operation. All operations were performed in a vertical laminar flow enclosure, but without a body exhaust system.

All patients gave informed consent to be included in the study, and approval was obtained from the local research ethics committee. Demographic data were recorded for each patient, and clinical and radiological evaluations were carried out at three months, and then annually until the latest follow-up. Both Oxford ${ }^{16}$ and Harris hip scores ${ }^{17}$ were recorded. For the Oxford hip score (OHS) the best possible score was 12 points and the worst 60 ; for the Harris hip score (HHS) the best possible score was 100 points and the worst zero points. At the final follow-up, the senior author (GCB) evaluated the radiographs using the technique of Johnston et $\mathrm{al}^{18}{ }^{18}$ and was blinded to the operating surgeon for these patients. Anteroposterior (AP) and lateral radiographs of the hip were evaluated for the inclination of the acetabular component on the AP view, the presence of retroacetabular, marginal or screw-associated osteolytic lesions, and radiolucent lines. The femoral components were then examined for osteolysis, radiolucent lines, migration, subsidence, fracture of the component and subsidence of the cement mantle. Linear wear was also calculated, and the measurements of wear and osteolysis were corrected for radiological magnification by determination of the real and radiological size of the femoral head as described by Livermore, Ilstrup and Morrey. ${ }^{19}$ The senior author examined the final AP and lateral radiographs of the hip for the presence of radiolucent lines and osteolysis according to DeLee and Charnley ${ }^{20}$ for the acetabular component, and Gruen, McNeice and Amstutz ${ }^{21}$ and Johnston et $\mathrm{al}^{18}$ for the femoral implant. The thickness of the polyethylene component for each combination of linear and femoral head was obtained from the manufacturers.

Radiological failure of the acetabular component was defined as a change of position either vertically or horizontally of more than $2 \mathrm{~mm}$, or a $2^{\circ}$ change in the angle of inclination taking the inter-teardrop line as a fixed landmark, as described by Massin, Schmidt and Engh. ${ }^{22}$ A radiolucent line of more than $2 \mathrm{~mm}$ affecting the whole interface between the acetabular component and bone was also classified as radiological failure. ${ }^{8}$ For the femoral component, subsidence of more than $5 \mathrm{~mm}$ was classified as loosening and osteolysis was defined as a radiolucent zone more than 2 mm wide. $^{10}$

Statistical analysis. Survival of the acetabular component was determined by Kaplan-Meier survival analysis and presented with 95\% confidence intervals (CI). Chi-squared tests were used to determine whether there were significant differences in the head size and polyethylene thickness between the failed and the surviving acetabular components. The inclination of the acetabular component was tested for normality using a Kolmogorov-Smirnov test, and a $t$-test was used to compare the inclination in the failed and surviving groups. Statistical significance was set at $\mathrm{p}<0.05$.

\section{Results}

The mean OHS at final follow-up was 20 (12 to 46) and the mean HHS was 81 (37 to 100). No patients died, and none were lost to follow-up.

Revisions. At a mean follow-up of 13.6 years (12 to 16), 11 hips (11 patients) had undergone acetabular revision. In total, five acetabular components were revised and six liners were changed. In two patients the acetabular component was revised for aseptic loosening, in one where it was 


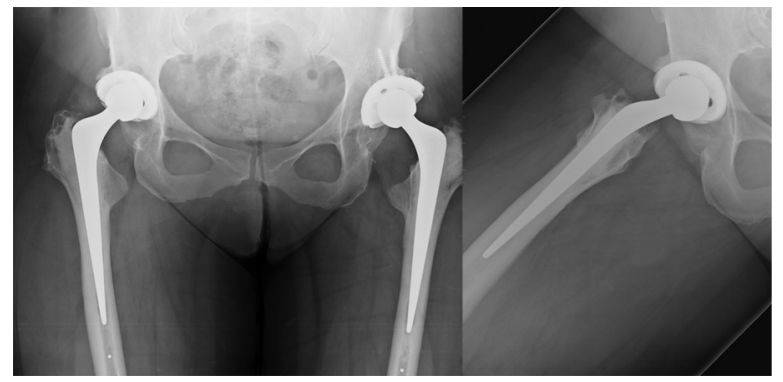

Fig. 1a

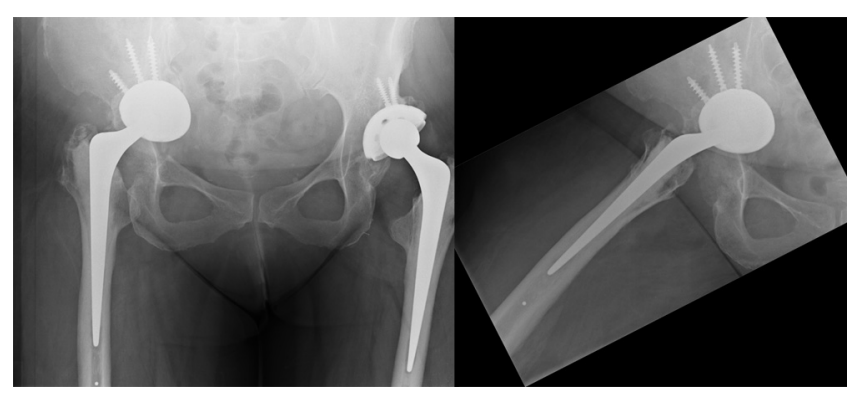

Fig. 1b

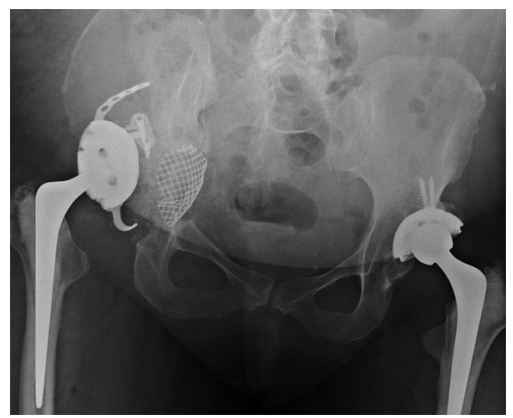

Fig. 1c

Anteroposterior and lateral radiographs of a patient with HarrisGalante acetabular components a) retroacetabular osteolysis is present, most marked in the right hip, b) following an initial revision in the presence of a medial wall defect, the right acetabular component has migrated into the pelvis and c) following further revision and medial wall grafting.

found not to be osseointegrated during exploration of a nonunion of the greater trochanter, and in one which was found to be loose in a patient with recurrent dislocation of the hip. The other reasons for revision were for deep infection, recurrent dislocation due to retroversion of the acetabular component and one for massive retroacetabular osteolysis (Fig. 1a). In this latter case, the component was revised to an uncemented implant which subsequently migrated into the pelvis because of a defect in the medial wall (Fig. 1b) and further revision with bone grafting to the medial wall was required (Fig. 1c).

Taking revision of the acetabular component for any reason as an endpoint, 65 of the 70 hips survived at a mean

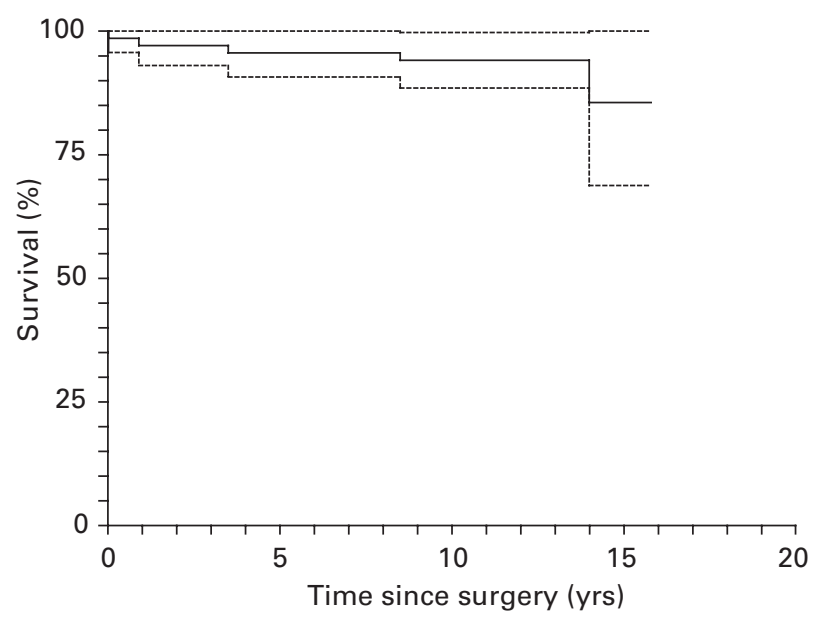

Fig. 2

Kaplan-Meier survival graph with 95\% confidence intervals taking revision of the acetabular component as the endpoint.

follow-up of 13.6 years (12 to 16 ), giving a cumulative survival of $94.0 \%$ (95\% CI 88.4 to 99.7 ) (Fig. 2).

Revision of the liner. Liners were exchanged in three patients due to polyethylene wear and where the acetabular components were found to be well fixed. Two were exchanged for longer posterior wall liners owing to recurrent dislocation and one because of deep infection which was successfully treated with a radical debridement. There were no cases of dislocation of the liner.

Taking revision of the acetabular component for any reason as an endpoint, 11 (11 patients) of the 70 hips were revised, giving a cumulative survival of $84.0 \%$ (95\% CI 74.5 to 93.5 ) at a mean of 13.6 years (12 to 16) (Fig. 3). Intention to revise. Radiologically, another four of the 70 acetabular components require revision imminently. The first patient has a circumferential lucent zone more than $2 \mathrm{~mm}$ wide around the acetabular component in the presence of a worn liner, although he continues to function well with an OHS of 14 and a HHS of 86. Two patients have retroacetabular osteolysis in DeLee and Charnley zones 1 and 2, although so far there has been no migration of the component. In the fourth patient there is linear wear of $7.5 \mathrm{~mm}$.

Including the additional four radiological failures, 15 of 70 acetabular components had or require revision, giving a cumulative survival or planned revision rate of $78.7 \%$ (95\% CI 67.4 to 90.1 ) at a mean of 13.6 years (12 to 16$)$ (Fig. 4).

Impending revision. Radiological analysis identified osteolysis around the femoral component in 27 hips (39\%), the most commonly in Gruen zone 7. As osteolysis in this zone is indicative of polyethylene wear, there was cumulative survival of $55.3 \%$ (95\% CI 40.6 to 70.0$)$ at 16 years for combined actual revision, intention to revise and impending revision surgery. 


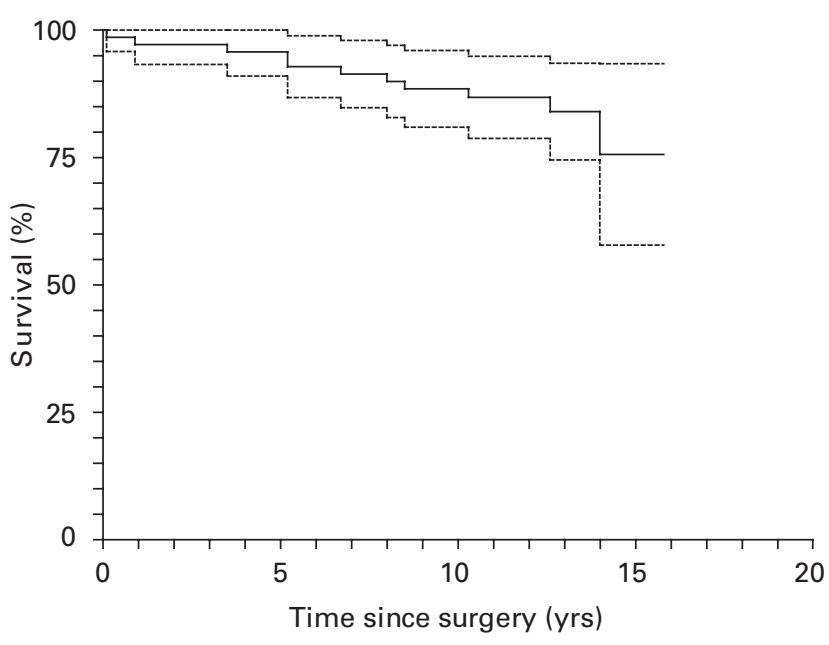

Fig. 3

Kaplan-Meier survival graph with 95\% confidence intervals taking revision of the acetabular component or liner as the endpoint.

Wear, lucent lines and acetabular osteolysis. There was no identifiable linear wear in 30 hips (43\%, 22 patients). One patient showed linear wear of $7.5 \mathrm{~mm}$ (28 mm head) and awaits revision surgery. The remaining 39 hips $(56 \%, 30$ patients) showed linear wear between $0.5 \mathrm{~mm}$ and $2 \mathrm{~mm}$. Three acetabular components $(4.3 \%)$ were revised for polyethylene liner wear. Two had a femoral head diameter of $32 \mathrm{~mm}$ and one of $28 \mathrm{~mm}$.

Non-progressive radiolucent lines of less than $2 \mathrm{~mm}$ were present around the acetabular component in 31 hips $(44 \%)$. Radiolucent lines around the periacetabular area of the femoral component were seen in only three hips (4\%).

Osteolysis was seen around the acetabular component in 13 hips (19\%), most commonly centred on the screws, and only ten hips $(14 \%)$ had neither radiolucent lines nor osteolysis around either component.

Other surgery. One patient had a hindquarter amputation because of peripheral vascular disease. Before this, his hip had functioned well for six years with no evidence of radiological loosening. One patient had excision of heterotopic bone.

Failure relating to head size, polyethylene thickness and acetabular component inclination. No statistically significant difference was found between head size alone and failure of the acetabular component (chi-squared test, $\mathrm{p}=0.37$ ). The mean initial polyethylene thickness of the liner was $8.7 \mathrm{~mm}$ (4.3 to 15.3 ). In the failed acetabular components the mean polyethylene thickness was $9.0 \mathrm{~mm}$, and in the surviving group it was $8.6 \mathrm{~mm}$. Comparing the acetabular components which had failed with those that had survived, using chi-squared tests, there was no statistically significant relationship between the thickness of the polyethylene component and survival of the acetabular component in the $22 \mathrm{~mm}(\mathrm{p}=0.792)$ and

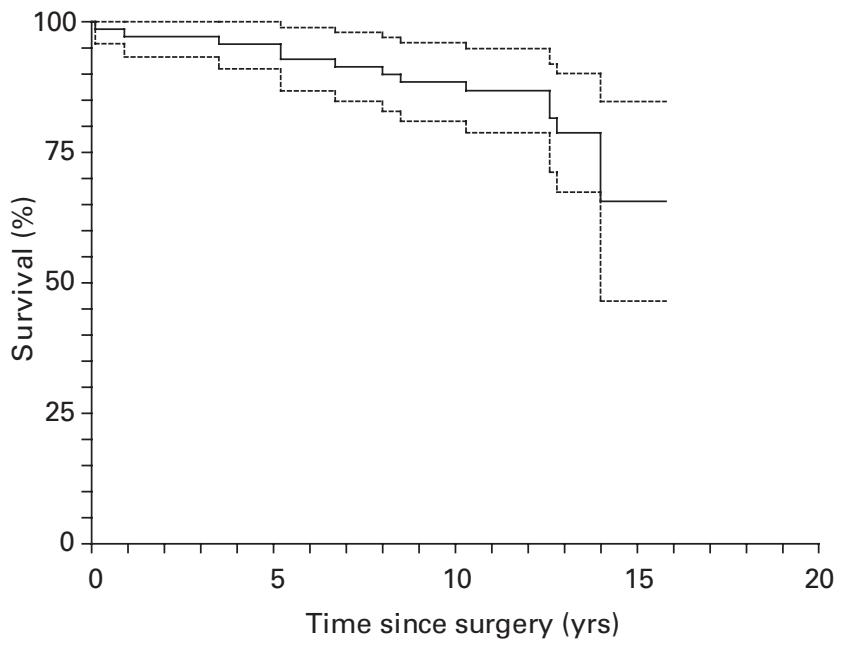

Fig. 4

Kaplan-Meier survival graph with 95\% confidence intervals taking revision of the acetabular component, liner and impending revision as the endpoint.

$28 \mathrm{~mm}(\mathrm{p}=0.479)$ head sizes, but there was statistically significantly greater failure in the $32 \mathrm{~mm}$ head group $(\mathrm{p}=0.009)$ with thinner polyethylene.

The mean inclination of the shell of the acetabular component in the frontal plane was $31.7^{\circ}\left(17^{\circ}\right.$ to $\left.58^{\circ}\right)$. In the failed acetabular components the mean inclination was $35.2^{\circ}\left(22^{\circ}\right.$ to $\left.45^{\circ}\right)$ and in the surviving group it was $32.0^{\circ}$ $\left(17^{\circ}\right.$ to $\left.58^{\circ}\right)$. The Kolmogorov-Smirnov test showed that the angles of inclination of the acetabular component were normally distributed: $t$-tests showed no association between component inclination and failure $(\mathrm{p}=0.594)$.

\section{Discussion}

The results of cementless acetabular components from selective studies in patients under 50 have shown revision rates between $0 \%$ and $14 \%$ after five to nine years (Table III). This study, with its longer period of follow-up, shows significantly higher rates of revision or planned revision. The rate rises significantly ten years after implantation. Berger et al, ${ }^{7}$ in their series of 79 hips followed up for a mean of 8.8 years, found no cases of aseptic loosening of the acetabular component and reported a combined rate of revision and acetabular osteolysis of $13 \%$. Similarly, Dunkley et $\mathrm{al}^{, 23}$ in a series of 55 Harris-Galante acetabular components followed up for a mean of seven years, had no cases of revision for aseptic loosening and an 18\% combined rate for revision and polyethylene wear. Although the series was also from this centre, the two cohorts of patients were not the same. The patients reported by Dunkley et $\mathrm{al}^{23}$ had surgery between 1986 and 1991.

The short- to medium-term success of hybrid THR in all age groups, with a cemented femoral component and an uncemented acetabular component, is well reported in the literature. In a series of 65 hybrid THRs by Harris ${ }^{13}$ 
Table III. Selected studies of uncemented acetabular components used in the under 50-year age group

\begin{tabular}{|c|c|c|c|c|c|c|c|c|}
\hline Authors & $\begin{array}{l}\text { Number of } \\
\text { patients (hips) }\end{array}$ & $\begin{array}{l}\text { Mean age of } \\
\text { )patients }\end{array}$ & $\begin{array}{l}\text { Mean follow-up } \\
\text { (yrs) }\end{array}$ & $\begin{array}{l}\text { Femoral } \\
\text { component }\end{array}$ & $\begin{array}{l}\text { Acetabular } \\
\text { component }\end{array}$ & Liner revisions & $\begin{array}{l}\text { Acetabular } \\
\text { component } \\
\text { revisions }\end{array}$ & Other $(\%)$ \\
\hline Berger et $\mathrm{al}^{7}$ & 79 & 37 (20 to 49 ) & 8.8 & $\begin{array}{l}\text { All Harris-Galante } \\
\text { (uncemented except } \\
\text { two) }\end{array}$ & Harris-Galante I & 2 & $\begin{array}{l}2 \text { (none for } \\
\text { aseptic } \\
\text { loosening) }\end{array}$ & $\begin{array}{l}7(7) \text { acetabular } \\
\text { osteolysis }\end{array}$ \\
\hline Dunkley et $\mathrm{al}^{23}$ & $50(55)$ & 41 (21 to 50$)$ & 7 & Various cemented & Harris-Galante I & $\begin{array}{l}4 \text { (all } 32 \mathrm{~mm} \\
\text { heads) }\end{array}$ & 0 & \\
\hline Kim and $\mathrm{Kim}^{8}$ & $55(64)$ & 43.4 & 9.4 & $\begin{array}{l}\text { Elite or Elite Plus } \\
\text { (cemented) }\end{array}$ & Duraloc & 0 & $\begin{array}{l}1 \text { due to } \\
\text { infection }\end{array}$ & $\begin{array}{l}4(6) \text { hips had } \\
\text { acetabular } \\
\text { osteolysis }\end{array}$ \\
\hline Dowdy et $\mathrm{al}^{11}$ & $36(41)$ & 42 (19 to 50$)$ & 5.3 & $\begin{array}{l}\text { Mallory-Head } \\
\text { (uncemented) }\end{array}$ & Mallory-Head & 0 & $\begin{array}{l}3 \text { ( } 2 \text { for } \\
\text { loosening } 1 \\
\text { for wear) }\end{array}$ & $\begin{array}{l}20(49) \text { had } \\
\text { polyethylene wear } \\
\text { and } 12(27) \text { had } \\
\text { acetabular osteo- } \\
\text { lysis }\end{array}$ \\
\hline Archibeck et al ${ }^{12}$ & $91(100)$ & 39 (14 to 50$)$ & 9 & $\begin{array}{l}\text { Multilock } \\
\text { (uncemented) }\end{array}$ & $\begin{array}{l}\text { Harris-Galante II } \\
\text { and Trilogy }\end{array}$ & $\begin{array}{l}5 \text { ( } 2 \text { for } \\
\text { dislocation } \\
\text { and } 2 \text { for } \\
\text { wear and } \\
\text { osteolysis) }\end{array}$ & $\begin{array}{l}8 \text { ( } 2 \text { for } \\
\text { aseptic } \\
\text { loosening, } 1 \\
\text { for osteolysis, } \\
1 \text { for wear) }\end{array}$ & \\
\hline Sporer et $\mathrm{al}^{9}$ & 37 (45) & 41 (25 to 49 ) & 8.2 & $\begin{array}{l}\text { lowa precoat } \\
\text { (cemented) }\end{array}$ & Harris-Galante I & 0 & 0 & $\begin{array}{l}8 \text { femoral } \\
\text { components } \\
\text { revised for aseptic } \\
\text { loosening }\end{array}$ \\
\hline Current study & $53(70)$ & 40 (19 to 49$)$ & 13.6 & Various cemented & Harris-Galante I & 6 & $\begin{array}{l}5 \text { and } 4 \text { more } \\
\text { planned for } \\
\text { revision }\end{array}$ & $\begin{array}{l}19 \% \text { acetabular } \\
\text { osteolysis } \\
39 \% \text { femoral } \\
\text { osteolysis }\end{array}$ \\
\hline
\end{tabular}

followed up for a mean of 6.6 years there were no revisions for acetabular or femoral aseptic loosening. The overall rate for revision and acetabular osteolysis was $6 \%$. Maloney et $\mathrm{al}^{24}$ reviewed 1081 primary THRs in 944 patients using Harris-Galante I cementless acetabular components with screw fixation and a mean follow-up of 81 months. The overall rate of pelvic osteolysis was $2.3 \%$, but this was inversely related to the age at the time of operation, with 15 hips $(22 \%)$ in patients younger than 50 having osteolysis at a minimum of ten years of follow-up.

Relatively few studies describe the long-term survival of uncemented acetabular components. In part this is due to regular changes in design of prostheses and the difficulties in following a cohort of patients over protracted periods. In a recent study of 93 uncemented RM acetabular components the cumulative survival with any acetabular revision as the endpoint was $82.7 \%$ at 19.8 years. ${ }^{25}$ Gaffey et $\mathrm{al}^{26}$ found no aseptic loosening or migration of the acetabular component in 70 hips at a follow-up of 13 to 15 years. Five had pelvic osteolysis and three had revision of a well-fixed acetabular component because of pelvic osteolysis secondary to polyethylene wear. They stated that Harris-Galante I acetabular components had less acetabular loosening than cemented Charnley components, although their rate of polyethylene wear was greater. In comparison, a 20- to 26-year follow-up of cemented Charnley low-friction arthroplasty in patients under 50 years of age showed a cumulative survival of $76 \%$ for the acetabular component for all causes of failure. ${ }^{27}$ This study has a significantly longer follow-up than those in Table III, which may account for the relatively high rate of revision of the acetabular component, planned and impending rates of revision and the high rate of acetabular and femoral osteolysis. The prevalence of femoral osteolysis $(39 \%)$ in our series is significantly higher than that in earlier reports, which ranged from $9 \%$ to $12 \% .^{10,28,29}$ Because of the use of lateral radiographs and Gruen zones 8 to 14, the sensitivity of detection of femoral osteolysis may have increased. This may have been under-reported in other series, as they used only AP views and the prosthesis itself may have concealed some osteolysis. In the series by Sporer et al, ${ }^{9}$ osteolysis of at least $5 \mathrm{~mm}$ was observed in 13 hips (35\%) in Gruen zone 7. This was associated with a rate of loosening of the femoral component of $24 \%$ at five to ten years in a similar population. Acetabular osteolysis with cementless acetabular components has been reported to be between $17 \%$ and $46 \%{ }^{7}$ In our series, acetabular osteolysis was present in 13 of 70 hips $(19 \%)$. This has led to revision of one acetabular component and another three cases where revision will be required. Periacetabular osteolysis and in Gruen zone 7 is related to polyethylene wear and hence failure of the acetabular component, and is the main factor influencing the longevity of the acetabular component in the young population. Importantly, the OHS and HHS of the patients in this study remain good, even in the presence of significant osteolysis, suggesting that the process is silent. Highly cross-linked polyethylene and hard-on-hard bearings such as ceramic and metal-on-metal articulations may improve the longevity of acetabular components in the future, although premature failure of one type of highly cross-linked polyethylene has been reported already. ${ }^{30,31}$ 
In this series there were no cases of dislocation of the liner, which relates to breakage of the tines constituting the locking mechanism between the polyethylene liner and the metal shell, and has been reported as a mode of failure of the Harris-Galante acetabular component. ${ }^{32,33}$

A large proportion of the revisions were for exchange of the liner. Accelerated wear of the liner has been shown to be more prevalent with large-diameter femoral heads. ${ }^{34}$ No statistically significant difference was found between head size alone and failure of the acetabular component in this study. Although revision of the liner is a more benign procedure than revision of the acetabular component, it has been associated with a high rate of dislocation. ${ }^{35}$ In the presence of liner wear and osteolysis well fixed acetabular components should probably be revised. ${ }^{36}$ There is no statistically significant difference between the surviving and the failed acetabular components with respect to acetabular inclination, although the limited number of hips in our series may not have been sufficient to demonstrate this. There was, however, a statistically significant difference in polyethylene thickness in the group with 32 $\mathrm{mm}$ heads, with thinner polyethylene being found in the failed components.

The best implant for the young patient requiring THR remains unresolved.Cemented acetabular components tend to fail over time by a process of aseptic loosening, and cause groin pain. High-density polyethylene-lined metal acetabular components such as the Harris-Galante rarely loosen, do not give groin pain, but do cause symptomatic silent osteolysis and loss of bone stock. Preservation of bone stock is the key objective in the young patient. This is one of the longest follow-up studies of uncemented acetabular components in patients under 50 years of age and indicates that these patients require regular clinical and radiological review so that reconstruction may be attempted before significant bone loss occurs.

The authors regret to announce the death of the first author, Matt Utting, whilst on a Fellowship in Australia. He will be sorely missed and is mourned by his colleages.

No benefits in any form have been received or will be received from a com mercial party related directly or indirectly to the subject of this article.

\section{References}

1. No authors listed. The Swedish Hip Arthroplasty Registry. Annual report 2005. http:// www.jru.orthop.gu.se (date last accessed 23 September 2008).

2. Lewthwaite SC, Squires B, Gie GA, Timperley AJ, Ling RS. The Exeter Universal hip in patients 50 years or younger at 10-17 years followup. Clin Orthop 2008;466:324-31.

3. Ballard WT, Callaghan JJ, Sullivan PM, Johnston RC. The results of improved cementing techniques for total hip arthroplasty in patients less than fifty years old: a tenyear follow-up study. J Bone Joint Surg [Am] 1994;76-A:959-64.

4. Barrack RL, Mulroy RD Jr, Harris WH. Improved cementing techniques and femoral component loosening in young patients with hip arthroplasty: a 12-year radiographic review. J Bone Joint Surg [Br] 1992;74-B:385-9.

5. Boeree NR, Bannister GC. Cemented total hip arthroplasty in patients younger than 50 years of age: ten- to 18-year results. Clin Orthop 1993;287:153-9.

6. Hedley AK, Clarke IC, Kozinn SC, et al. Porous ingrowth fixation of the femoral component in a canine surface replacement of the hip. Clin Orthop 1982;163:300-11.

7. Berger RA, Jacobs JJ, Quigley LR, Rosenberg AG, Galante J0. Primary cementless acetabular reconstruction in patients younger than 50 years old: 7 - to 11 -year results. Clin Orthop 1997;344:216-26.
8. Kim YH, Kim VE. Results of Harris-Galante cementless hip prosthesis. J Bone Joint Surg [Br] 1992;74-B:83-7.

9. Sporer SM, Callaghan JJ, Olejniczak JP, Johnston RC. Hybrid total hip arthroplasty in patients under the age of fifty: a five- to ten-year followup. J Arthroplasty 1998;13:484-

10. Kim YH, Kook HK, Kim JS. Total hip replacement with a cementless acetabular component and a cemented femoral component in patients younger than fifty years of age. $J$ Bone Joint Surg [Am] 2002;84-A:770-4.

11. Dowdy PA, Rorabeck CH, Bourne RB. Uncemented total hip arthroplasty in patients 50 years of age or younger. J Arthroplasty 1997;12:853-62.

12. Archibeck MJ, Surdam JW, Schultz SC Jr, Junick DW, White RE. Cementless total hip arthroplasty in patients 50 years or younger. J Arthroplasty 2006;21:476-83.

13. Harris WH. Hybrid total hip replacement: rationale and intermediate clinical results. Clin Orthop 1996;333:155-64

14. Crowther JD, Lachiewicz PF. Survival and polyethylene wear of porous-coated acetabular components in patients less than fifty years old: results at nine to fourteen years. $J$ Bone Joint Surg [Am] 2000;84-A:729-35.

15. Bourne RB, Rorabeck CH, Skutek M, et al. The Harris Design-2 total hip replacement fixed with so-called second-generation cementing techniques: a ten to fifteen-year followup. J Bone Joint Surg [Am] 1998;80-A:1775-80.

16. Dawson J, Fitzpatrick R, Carr A, Murray D. Questionnaire on the perceptions of patients about total hip replacement. J Bone Joint Surg [Br] 1996;78-B:185-90.

17. Harris WH. Traumatic arthritis of the hip after dislocation and acetabular fracture: treatment by mold arthroplasty: an end-result study using a new method of result evaluation. $J$ Bone Joint Surg [Am] 1969;51-A:737-55.

18. Johnston RC, Fitzgerald RH Jr, Harris WH, et al. Clinical and radiographic evaluation of total hip replacement: a standard system of terminology for reporting results. J Bone Joint Surg [Am]1990;72-A:161-8.

19. Livermore J, Ilstrup D, Morrey B. Effect of femoral head size on wear of polyethylene acetabular component. J Bone Joint Surg [Am] 1990;72-A:518-28.

20. DeLee JG, Charnley J. Radiological demarcation of cemented sockets in total hip replacement. Clin Orthop 1976;121:20-32.

21. Gruen TA, McNiece GM, Amstutz HC. "Modes of failure" of cemented stem-type femoral components: a radiographic analysis of loosening. Clin Orthop 1979;141:17-27.

22. Massin P, Schmidt L, Engh CA. Evaluation of cementless acetabular component migration: an experimental study. J Arthroplasty 1989;4:245-51.

23. Dunkley AB. Eldridge JD, Lee MB, Smith EJ, Learmonth ID. Cementless acetabular replacement in the young. Clin Orthop 2000;376:149-55.

24. Maloney WJ, Galante J0, Anderson M, et al. Fixation, polyethylene wear and pelvic osteolysis in primary total hip replacement. Clin Orthop 1999;369:157-64.

25. Ihle M, Mai S, Pfluger D, Siebert W. The results of the titanium-coated RM acetabular component at 20 years: a long-term follow-up of an uncemented primary total hip replacement. J Bone Joint Surg [Br] 2008;90-B:1284-90

26. Gaffey JL, Callaghan JJ, Pedersen DR, et al. Cementless acetabular fixation at fifteen years: a comparison with some surgeon's results following acetabular fixation with cement. J Bone Joint Surg [Am] 2004;86-A:257-61.

27. Halley DK, Glassman AH. Twenty to twenty-six-year radiographic review in patients less than 50 years of age or younger with cemented Charnley low-friction arthroplasty. J Arthroplasty 2003;18:79-85.

28. Barrack RL, Mulroy RD Jr, Harris WH. Improved cementing techniques and femoral component loosening in young patients with hip arthroplasty: a 12-year radiographic review. J Bone Joint Surg [Br] 1992;74-B:385-9.

29. Zicat B, Engh CA, Gokcen E. Patterns of osteolysis around total hip components inserted with or without cement. J Bone Joint Surg [Am] 1995;77-A:432-9.

30. Tower SS, Currier JH, Currier BH, et al. Rim cracking of the cross-linked longevity polyethylene acetabular liner after total hip arthroplasty. J Bone Joint Surg [Am] 2007;89A:2212-17.

31. Furmanski J, Gupta S, Chawan A, et al. Aspherical femoral head with highly crosslinked ultra-high molecular weight polyethylene surface cracking: a case report. J Bone Joint Surg [Am] 2007;89-A:2266-70.

32. Peters CL, Sullivan CL. Locking mechanism failure in the Harris-Galante porous acetabular component associated with recurrent hip dislocation. J Arthroplasty 2002;17:507-15.

33. White SP, Blom AW, Lee M, Smith EJ. The crescent sign: dissociation of the polyethylene liner from a modular acetabular component in total hip arthroplasty. Skeletal Radiology 2005;34:620-4.

34. Blom AW, Madhavan P, Lee M, Learmonth ID, Smith EJ. Thirty-two millimetre heads and accelerated polyethylene wear in total hip arthroplasty. Hip Internationa/ 2006;16:207-9.

35. Blom AV, Astle L, Loveridge J, Learmonth ID. Revision of an acetabular liner revision has a high risk of dislocation. J Bone Joint Surg [Br] 2005;87-B:1636-8.

36. Lie SA, Hallan G, Furnes O, Havelin LI, Engesaeter LB. Islolated acetabular liner exchange compared with complete acetabular component revision in revision of primary uncemented acetabular components: a study of 1649 revisions from the Norwegian Arthroplasty Register. J Bone Joint Joint Surg [Br] 2007;89-B:591-4. 